\title{
Perfil das Exportações Fluminenses: uma análise da pauta exportadora no período 1990/2013
}

Roberta Rodrigues Salvini

Norberto Martins ${ }^{1}$

\section{Resumo}

A estrutura das exportações fluminenses passou por grandes modificações devido às transformações ocorridas no âmbito das atividades petrolíferas à abertura do comércio internacional em meados da década de 1990. Nesse sentido, o presente trabalho analisou o comportamento e a estrutura do setor exportador do Estado do Rio de Janeiro no período de 1990 a 2013. Os resultados apontaram para uma redução na participação das exportações do setor de ferro fundido, ferro e aço, e um aumento da parcela correspondente ao setor de combustíveis minerais, óleos minerais e matérias betuminosas. Demonstrou também a concentração da pauta exportadora no setor de combustíveis minerais. Além disso, verificouse que os Estados Unidos são o principal parceiro comercial do Rio de Janeiro, contudo, não foi confirmada a existência de concentração em relação aos destinos das exportações.

Palavras-chave: Exportações fluminenses; Concentração; Diversificação da pauta exportadora

\section{Abstract}

The structure of exports of Rio de Janeiro underwent major modifications due to changes occurring within the oil opening of international trade activities in the mid-1990s. This sense, this paper analyzed the behavior and the structure of the export sector of the state of Rio de Janeiro from 1990 to 2013. The results pointed to a decline in the share of exports of Iron and Steel, and an increase in the portion corresponding to the Mineral Fuels, Oils and Distillation Products. Also demonstrated the concentration in the export basket of Mineral Fuels industry. Furthermore, it was found that the United States are the main trading partner of Rio de Janeiro, however, was not confirmed the existence of concentration in relation to export destinations.

Keywords: Fluminense Exports; Concentration; Diversification of export basket

\section{Introdução}

Do ponto de vista do comércio exterior, podem-se distinguir, basicamente, duas 
estratégias de crescimento econômico. A primeira, voltada para fora, tem por base a expansão das exportações, segundo as vantagens comparativas do país, e a substituição seletiva de importações, com a economia relativamente aberta ao mercado internacional. A segunda apoia-se na substituição de importações, com a economia fechada, o crescimento econômico efetuando-se com base no mercado interno e as exportações crescendo marginalmente (Diniz, 2010).

Nesse contexto, o Brasil, ao final dos anos de 1980, passou por transformações estruturais e liberalizantes, como forma de adequar a economia interna ao novo patamar de desenvolvimento econômico mundial. De acordo com Silva e Hidalgo (2010), a alteração na estrutura das exportações, com maior participação de produtos agregados em tecnologia, estaria relacionada ao aumento da capacidade de inserção no mercado internacional e a ganhos de competitividade, que alguns setores industriais teriam adquirido após o processo de abertura.

As mudanças ocorridas ao fim da década de 1980 e início dos anos 1990 também geraram reflexos sobre a economia fluminense. Deve-se somar a isso, a edição da Emenda Constitucional $\mathrm{n}^{\circ} 9$, que ocorreu em 1995 e abriu o mercado brasileiro para empresas privadas nacionais e internacionais no que se refere às atividades da indústria do petróleo. Como resultado, de acordo com os dados do ALICEWEB (2014), enquanto as exportações do Rio de Janeiro cresceram em uma média anual de 34,05\%, no período compreendido entre os anos de 2000 e 2008, o PIB do estado a preços correntes aumentou 12,14\% ao ano no mesmo intervalo de tempo. Isso demonstra a importância que o comércio externo pode representar para o desenvolvimento econômico do Estado do Rio de Janeiro.

Diante desse quadro se faz necessário um estudo mais aprofundado sobre a pauta exportadora fluminense, para que o estado possa se posicionar com máxima eficiência no cenário econômico internacional. Dentro dessa perspectiva, o presente trabalho analisou a estrutura e o comportamento das exportações fluminenses, no período de 1990 a 2013. Para tal fim, mensurou-se o grau de concentração de produtos e de destinos das exportações, o tipo de comércio e os setores fortes na pauta de exportação do Estado do Rio de Janeiro.

O trabalho encontra-se estruturado em quatro seções, além desta Introdução. Na primeira seção, foi apresentado o modelo que dá base teórica à pesquisa. Na segunda, foi apresentada a metodologia utilizada para cálculo dos índices. Na terceira seção, foram apresentados os resultados e discussão da pesquisa e, por fim, as conclusões do trabalho.

\section{Referencial teórico}

Diante da necessidade de produzir mais bens, a fim de suprir a crescente demanda mundial, o comércio internacional é extremamente necessário devido aos ganhos mutuamente gerados. De acordo com Silva (2005), com o comércio as nações podem se especializar em bens com os quais são mais competitivas, além de obterem economias de escala na produção.

Desta forma, algumas teorias analisam o comércio internacional, começando com Adam Smith e a Teoria da Vantagem Absoluta. Posteriormente, David Ricardo ampliou a discussão feita por Smith com sua Teoria das Vantagens Comparativas do Comércio, com uma análise mais abrangente e explicativa da existência e importância do comércio internacional. O seu diferencial, em relação ao modelo de Smith, é que para ele o país pode obter ganhos com comércio mesmo não tendo vantagens absolutas. $\mathrm{O}$ mais relevante, segundo Ricardo, 
é possuir vantagens comparativas de comércio, porque, com elas, haverá a ampliação do comércio e dos benefícios devido ao aumento da quantidade produzida mundialmente e também do aumento do consumo. E os benefícios dessa comercialização só existem devido à diferença na produtividade do trabalho nos países (Krugman; Obstfeld, 2005).

Posteriormente, Paul Samuelson e Ronald Jones desenvolveram o modelo de fatores específicos. A diferença do modelo para o de Ricardo é que o mesmo permite outros fatores de produção além do trabalho, o que admite a formulação de uma curva de oferta ao invés de uma reta, sendo que o trabalho é considerado um fator móvel e os outros fatores são específicos. E o trabalho foi ligado à melhoria de produtividade, sendo que, quanto maior o nível de trabalho empregado, para dado nível de capital, melhor a produtividade. E, se ao adicionar mão de obra não houver aumento de capital, haverá retornos decrescentes. Além disso, o relevante no modelo é que os setores exportadores de produtos intensivos em fatores específicos abundantes no país ganham com o comércio e, em contrapartida, há perda para os mesmos produtores no país importador (Krugman; Obstfeld, 2005).

Segundo Krugman e Obstfeld (2005), os economistas Eli Heckscher e Bertil Ohlin procuravam explicar a influência mútua dos fatores específicos de cada país, quando desenvolveram a teoria que ficou conhecida como Teoria de Heckscher-Ohlin ou Teoria de Dotação de Fatores. As pressuposições de H-O são de que a economia esteja funcionando em pleno emprego, sem ganhos de escala, restrições comercias e com tecnologia idêntica nos países. Através de dois fatores de produção móveis, os países definem a intensidade utilizada de cada fator, na procura de exportar, principalmente, bens que utilizam fatores abundantes e importar bens que utilizam fatores escassos (Santos, 2011).

As teorias clássicas se adéquam para explicar a pauta exportadora fluminense, que consiste principalmente em commodities minerais. Entretanto, o comércio torna-se mais complexo e, segundo T. A. Silva, "[...] outros fatores passam a interferir na dinâmica do comércio internacional como, por exemplo, os contratos internacionais, a crescente exigência por qualidade, presença de barreiras tarifárias e não tarifárias, entre outros” (Silva, 2005, p. 36).

\section{Metodologia}

Os dados utilizados estão disponíveis no Sistema de Análise das Informações de Comércio Exterior, disponibilizados pela Secretaria de Comércio Exterior (SECEX), do Ministério do Desenvolvimento, Indústria e Comércio (MDIC). São referentes aos valores em dólares FOB (Free on board) das exportações do Estado do Rio de Janeiro, por capítulo da pauta.

\subsection{Mensuração do grau de intensidade tecnológica}

Segundo Furtado e Carvalho (2005), a classificação por intensidade tecnológica permitiria diferenciar as estruturas entre países desenvolvidos e em desenvolvimento. Nas regiões desenvolvidas, a intensidade tecnológica deixa visível a velocidade de adaptação destas às novas tecnologias. Já nas nações em desenvolvimento, os esforços referentes ao processo de transferência internacional de tecnologia se tornam mais evidentes.

O critério que será utilizado tem por base a Classificação da Organização para Cooperação e Desenvolvimento Econômico (OCDE), adaptada pela SECEX/MDIC, onde os setores são divididos em quatro categorias: 
i) Alta intensidade tecnológica: setor aeroespacial, farmacêutico, de informação, eletrônica, telecomunicações e instrumentos;

ii) Média-alta intensidade tecnológica: setores de material elétrico, veículos automotores, química (excluído o setor farmacêutico), ferroviários, equipamentos de transporte, máquinas e equipamentos;

iii) Média-baixa intensidade tecnológica: setores de construção naval, borracha e produtos plásticos, coque, produtos refinados metálicos, metalurgia básica e produtos metálicos;

iv) Baixa intensidade tecnológica: outros setores e de reciclagem, madeira, papel e celulose, editorial e gráfica, alimentos, bebidas e fumo, têxtil de confecção, couro e calçado.

\subsection{Indicadores de grau de concentração e tipo de comércio}

Quando um país apresenta suas exportações concentradas em poucos produtos e em poucos destinos, a sua economia está sujeita a flutuações na demanda, o que implica mudanças bruscas na receita das exportações. Sendo assim, o coeficiente de Gini-Hirchman é utilizado para mensurar a concentração das exportações, tanto em relação aos produtos quanto aos mercados de destino.

O índice de concentração por produtos (ICP) é calculado conforme a expressão abaixo:

$$
\mathrm{ICP}=\sqrt{\sum_{i}\left[\frac{X_{i j}}{X_{j}}\right]^{2}}
$$

em que representa as exportações do bem i pelo país j, e representa as exportações totais do país j.

Seu valor está definido no intervalo entre 0 e 1. Um índice ICP próximo à unidade indica que o país tem suas exportações concentradas em poucos produtos. Nesse caso, argumenta-se que o país terá maior instabilidade em suas receitas cambiais. De outro modo, um índice ICP próximo de zero reflete maior diversificação de produtos na pauta de exportações.

Outro índice, utilizado para mensurar a concentração dos parceiros comerciais, é o índice de concentração por países de destino:

$$
\mathrm{ICD}=\sqrt{\sum_{i}\left[\frac{X_{i j}}{X_{J}}\right]^{2}}
$$

em que , neste caso, representa o total das exportações do país j para o país i e , o total das exportações do país j. Um valor de ICD próximo à unidade representa uma alta concentração em relação aos destinos, o que poderia indicar maior vulnerabilidade em termos de barreiras à entrada de produtos impostas pelos poucos parceiros. Por sua vez, um ICD próximo de zero reflete uma participação mais equilibrada nos diversos mercados. Em tal circunstância, o país estará menos sujeito a flutuações na receita de suas exportações (Love, 1979).

\subsection{Indicador de setores tradicionais}

Um indicador que permite classificar se determinado setor exportador é tradicional ou não é a Função de Experiência das Exportações Acumuladas, que é obtida por:

$$
c_{i t}=\frac{\sum_{i=t_{0}}^{t} e_{i t}}{\sum_{i=t_{0}}^{t_{1}} e_{i t}}
$$

em que representa as exportações de um país do produto i no ano t.

Os valores dos períodos inicial e final da amostra são representados por e . Tal função assume o valor de 0 ou próximo de zero para períodos iniciais da amostra, e valores próximos ou igual a 1 no final da amostra. Quando os valores da função crescem mais rapidamente no início do período o produto é considerado não tradicional, e quando os valores crescem no final do período o produto é considerado tradicional. 


\section{Resultados e discussão}

O Estado do Rio de Janeiro, nos últimos anos, apresentou alterações em termos de intensidade tecnológica de suas exportações. Esse fato pode ser observado na Tabela 1, que apresenta para quatro anos, 1998, 2004, 2010 e 2013, o número de setores e a participação destes no comércio internacional segundo a intensidade tecnológica.

Tabela 1

Comércio Exterior do Estado do RJ segundo a Intensidade Tecnológica nos anos de 1998, 2004, 2010 e 2013

\begin{tabular}{|c|c|c|c|c|c|c|c|c|}
\hline \multirow{3}{*}{ DISCRIMINAÇÃO } & \multicolumn{8}{|c|}{ EXPORTAÇÕES } \\
\hline & \multicolumn{2}{|c|}{1998} & \multicolumn{2}{|c|}{2004} & \multicolumn{2}{|c|}{2010} & \multicolumn{2}{|c|}{2013} \\
\hline & $\mathrm{N}^{\circ *}$ & $\%$ * & $\mathrm{N}^{\circ}$ & $\%$ & $\mathrm{~N}^{\circ}$ & $\%$ & $\mathrm{~N}^{\circ}$ & $\%$ \\
\hline \multicolumn{9}{|l|}{ Intensidade Tecnológica } \\
\hline 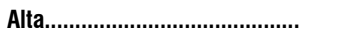 & 6 & 9,6 & 6 & 3,1 & 6 & 1,8 & 6 & 1,87 \\
\hline 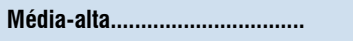 & 14 & 24,8 & 14 & 49 & 14 & 85,6 & 14 & 70,71 \\
\hline 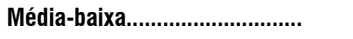 & 16 & 44,6 & 16 & 35,9 & 16 & 8,3 & 16 & 21,22 \\
\hline \multirow[t]{2}{*}{ Baixa................................................ } & 60 & 12 & 60 & 3,6 & 59 & 1,3 & 60 & 1,4 \\
\hline & \multicolumn{8}{|c|}{ IMPORTAÇÕES } \\
\hline \multirow{2}{*}{ DISCRIMINAÇÃO } & \multicolumn{2}{|c|}{1998} & \multicolumn{2}{|c|}{2004} & \multicolumn{2}{|c|}{2010} & \multicolumn{2}{|c|}{2013} \\
\hline & $\mathrm{N}^{\circ}$ & $\%$ & $\mathrm{~N}^{\circ}$ & $\%$ & $\mathrm{~N}^{\circ}$ & $\%$ & $\mathrm{~N}^{\circ}$ & $\%$ \\
\hline \multicolumn{9}{|l|}{ Intensidade Tecnológica } \\
\hline 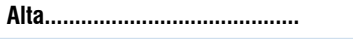 & 6 & 19,9 & 6 & 16,9 & 6 & 16,8 & 6 & 17,6 \\
\hline 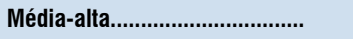 & 14 & 52,2 & 14 & 69,6 & 14 & 63,8 & 14 & 65,3 \\
\hline 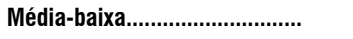 & 16 & 9,2 & 16 & 5,8 & 16 & 10 & 16 & 9,4 \\
\hline 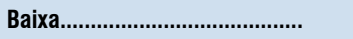 & 60 & 18,6 & 60 & 7,7 & 60 & 9,3 & 60 & 7,7 \\
\hline
\end{tabular}

Fonte: Elaboração própria a partir de dados do ALICEWEB (2014)

*No: Número de setores; \%: participação dos setores nas exportações.

De acordo com os dados da Tabela 1, pode-se observar que, nas exportações, ocorreu uma redução da participação dos setores de alta, média-baixa e baixa intensidade tecnológica, e um consequente aumento na parcela correspondente aos setores de média-alta intensidade tecnológica. ${ }^{2}$ Percebe-se também que a faixa de classificação que inclui o maior número de setores, a de baixa intensidade tecnológica, é a que possui a menor participação no total das exportações no ano de 2013. Com relação às importações, verificou-se que a maior contribuição foi a dos setores de média-alta intensidade tecnológica, nos quatro anos considerados.

Realizando uma análise mais detalhada, os setores de baixa intensidade tecnológica com maior participação nas exportações nos anos de 1990 a 2013 foram: o de preparações de carne, peixes e crustáceos; papel e cartão; e vestuário e seus acessórios, exceto de malhas. Entre os setores de média-baixa intensidade tecnológica que se destacaram estão: ferro fundido, ferro e aço; borracha e suas obras; embarcações e estruturas flutuantes; obras de ferro fundido, ferro ou aço; plásticos e suas obras; alumínio e suas obras; e pérolas, pedras preciosas e semipreciosas e semelhantes. No caso dos setores de média-alta intensidade tecnológica, devem ser ressaltados: combustíveis minerais, óleos minerais e matérias betuminosas; reatores nucleares, máquinas, instrumentos mecânicos e suas partes; produtos químicos orgânicos; veículos automóveis, e outros veículos terrestres; produtos diversos das

2 Deve-se ressaltar que uma seção da pauta exportadora não pôde ser incluída na Tabela 1, a de Transações especiais, por não se enquadrar na classificação quanto ao grau de intensidade tecnológica. Porém ela está no grupo dos vinte setores com maior participação nas exportações em todo o período analisado neste trabalho. 
indústrias químicas; e óleos essenciais e resinóides, produtos de perfumaria e preparações cosméticas. E, por último, os setores de alta intensidade tecnológica com maior participação foram: instrumentos e aparelhos de óptica, instrumentos e aparelhos médico-cirúrgicos, suas partes e acessórios; produtos farmacêuticos; e máquinas, aparelhos e materiais elétricos, e suas partes; aparelhos de gravação ou de reprodução de imagens e de som em televisão, e suas partes e acessórios.

A maior participação na pauta exportadora foi mantida pelo setor de ferro fundido, ferro e aço até o ano de 2001, quando o setor de combustíveis minerais assume tal posição, e permanece nesta até o ano de 2013. Em seu primeiro ano como o principal setor da pauta, as exportações de combustíveis minerais representavam 42,6\% do valor total exportado e, em 2010, essa parcela já atingia os 79,3\%, indicando uma concentração das exportações nos produtos desse setor.

O setor petrolífero brasileiro passou por mudanças radicais em meados dos anos de 1990. De acordo com Faria Neto (2003), a edição da Emenda Constitucional n9 9 , que ocorreu em 1995, abriu o mercado brasileiro para empresas privadas nacionais e internacionais no que se refere às atividades da indústria do petróleo, que antes constituíam monopólio da União e eram exercidas com exclusividade pela Petrobrás. A referida abertura foi consolidada com a Lei 9.478 de 1997 que, além de regular o fim do monopólio por parte da Petrobrás, criou a Agência Nacional de Petróleo (ANP) e o Conselho Nacional de Política Energética (CNPE).

Lucchesi (1998) afirma que, em função da bacia de Campos dos Goytacazes, a produção petrolífera brasileira chega aos 182 mil barris ao dia. Porém, segundo Faria Neto (2003), o principal argumento utilizado à época da edição da Emenda Constitucional $n^{\circ} 9$ era de que, apesar da descoberta de enormes jazidas em Campos, o Brasil ainda era importador do produto e carecia de recursos para desenvolver a sua indústria petrolífera.

O aumento da produção reduziu a dependência de petróleo importado em 36,8\% em 1999 (Ordõnez, 2009). E em 2006 o país atingiu a autossuficiência, com a entrada em operação da plataforma P-50, no campo de Albacora Leste (Bacia de Campos). De acordo com Soares et al. (2010), o próximo desafio seria a autossuficiência em derivados. Todas essas transformações geraram impactos sobre as exportações fluminenses, levando o setor de combustíveis minerais a ser o principal na pauta exportadora do Estado do Rio de Janeiro (Figura 1). 
Figura 1

Índice de Concentração por Produtos (ICP) - Rio de Janeiro (1990-2013)

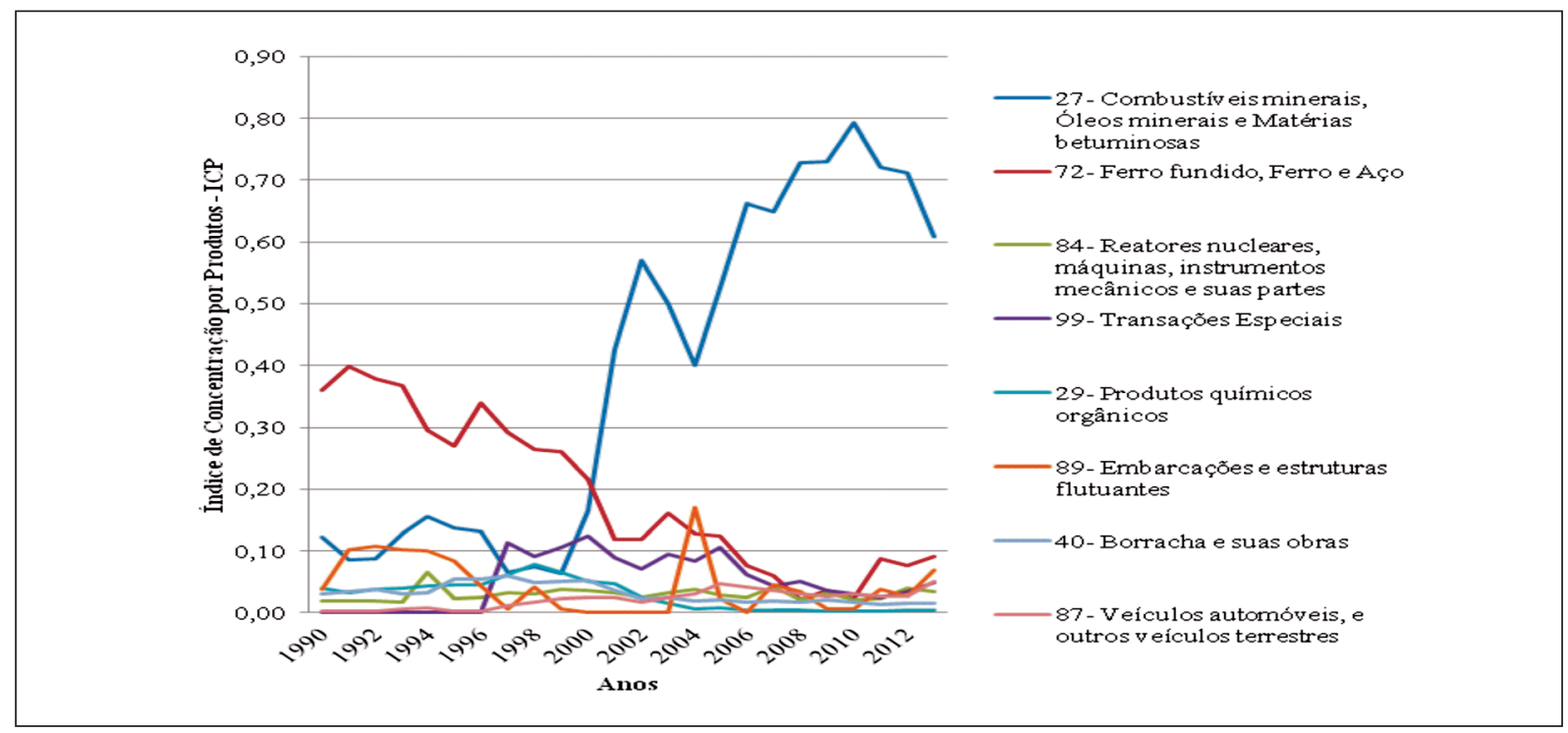

Fonte: Elaboração própria a partir de dados do ALICEWEB, (2014).

O índice de concentração por produtos, apresentado na Figura 1, indicou uma concentração das exportações no setor de combustíveis minerais, óleos minerais e matérias betuminosas, fechando o ano de $2013 \mathrm{com}$ o índice acima de 0,5, que é o limite para que haja concentração. A queda da participação do setor ferro fundido, ferro e aço nas exportações fluminenses, como já foi mencionado anteriormente, pode ser observada ao se analisar o seu ICP. Apesar da redução apresentada a partir de 2010, o ICP dos combustíveis minerais cresceu substancialmente, sendo o setor responsável, entre 2008 e 2012, por mais de $70 \%$ do valor das exportações do Rio de Janeiro.

De acordo com o trabalho de Silva e Hidalgo (2010), que faz uma análise das exportações brasileiras, os produtos com maior participação na pauta, no período de 2001 a 2006 foram veículos automóveis, caldeiras e máquinas, e ferro e aço, que também têm destaque na pauta fluminense, como pode ser observado na Figura 1. O setor de combustíveis, óleos e ceras minerais, principal nas exportações do Rio de janeiro, ocupa a quinta posição na pauta exportadora brasileira. Contudo, ao contrário das exportações fluminenses, que são concentradas neste setor, a pauta brasileira é diversificada em seus produtos.

Contudo, cabe ressaltar que as exportações do Rio de Janeiro seguem uma tendência apresentada pelo Brasil, que segundo Pinto (2011) consiste na regressão do padrão de comércio externo, já que a maior parte das exportações é composta por bens intensivos em recursos naturais, além do baixo conteúdo tecnológico dos produtos manufaturados exportados. Ainda, o mesmo autor destaca o processo de reprimarização pelo qual passam as exportações do país. Isso pode ser confirmado pelo aumento na participação de produtos básicos nas exportações brasileiras e consequente queda na contribuição de produtos semimanufaturados e manufaturados entre 2003 e 2009.

Mattos e Carcanholo (2012) realçam as dificuldades estruturais que o Brasil enfrenta para gerar diferenciais de produtividade no cenário econômico, que fazem com que sua inserção no comércio internacional não se dê da forma desejada. Os avanços na produtividade que alguns setores apresentam têm por base a redução do emprego e/ou ganhos marginais em termos de redução de custos salariais, viabilizados por um mercado de trabalho exageradamente flexível a favor do capital. Todavia, não tem acontecido de melhorias relevantes na produtividade 
serem alcançadas através de investimentos em ciência e tecnologia.

Já a Figura 2 apresenta o índice de concentração por países de destino para sete países que se sobressaíram como importadores de produtos fluminenses, entre os anos de 1990 a 2013.

Figura 2

Índice de Concentração por Países de Destino (ICD)

Rio de Janeiro (1990-2013)

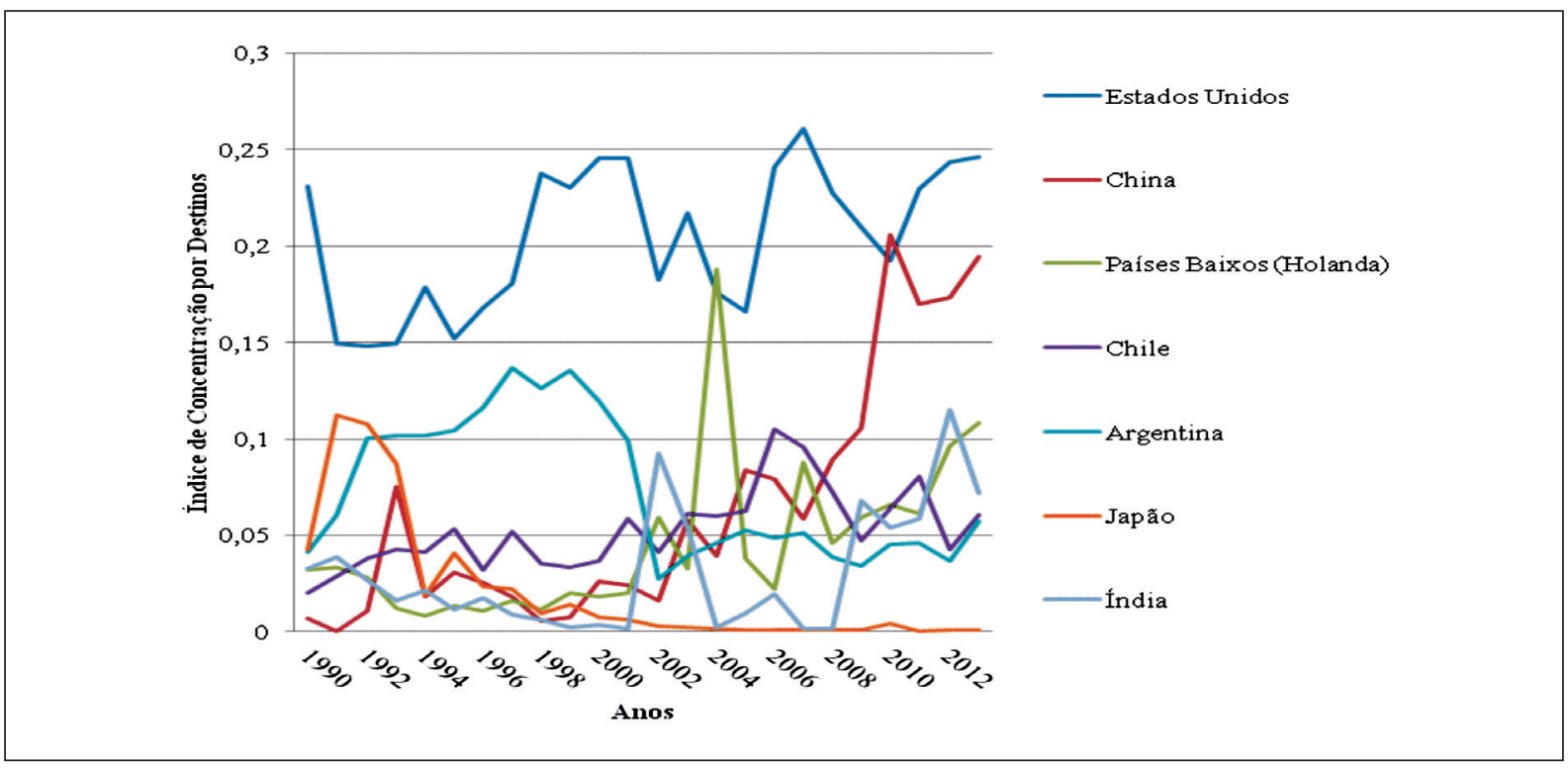

Fonte: Elaboração própria a partir de dados do ALICEWEB (2014).

O índice de concentração por países de destino registrou como principal parceiro comercial do Rio de Janeiro os Estados Unidos, sendo ultrapassados nas importações do estado somente em 2004 pelos Países Baixos (Holanda), e em 2010 pela China. Porém, o índice não apontou para nenhuma concentração em relação a esses países, alcançando seu maior valor em 2007, que foi de 0,26 . Isso demonstra como as exportações fluminenses são diversificadas no que tange ao destino de seus produtos. Esse aspecto é importante, pois aponta que o setor exportador fluminense não está sujeito às condições de demanda dos países importadores.

Vale lembrar que nos últimos anos tem aumentado a influência econômica, em termos de comércio, investimento direto e crédito, da China sobre a América Latina, enquanto a influência econômica dos Estados Unidos tem decaído principalmente nos países da América do Sul. No caso do Brasil, houve um aumento significativo da participação das exportações destinadas à China entre 2000 e 2010, e diminuição da participação das exportações destinadas aos Estados Unidos, assim como ocorreu no Rio de Janeiro (Pinto, 2013).

Por sua vez, a análise da tradicionalidade dos setores exportadores permite estimar se a participação de determinado setor nas exportações irá reduzir nos próximos anos, caso em que este setor é não tradicional, ou mesmo aumentar, quando este se apresenta como tradicional. A Figura 3 exibe as exportações do Estado do Rio de Janeiro classificadas em tradicionais ou não tradicionais, entre os anos de 1989 e 2013. 
Figura 3

Exportações tradicionais e não tradicionais do Estado do Rio de Janeiro (1989-2013)

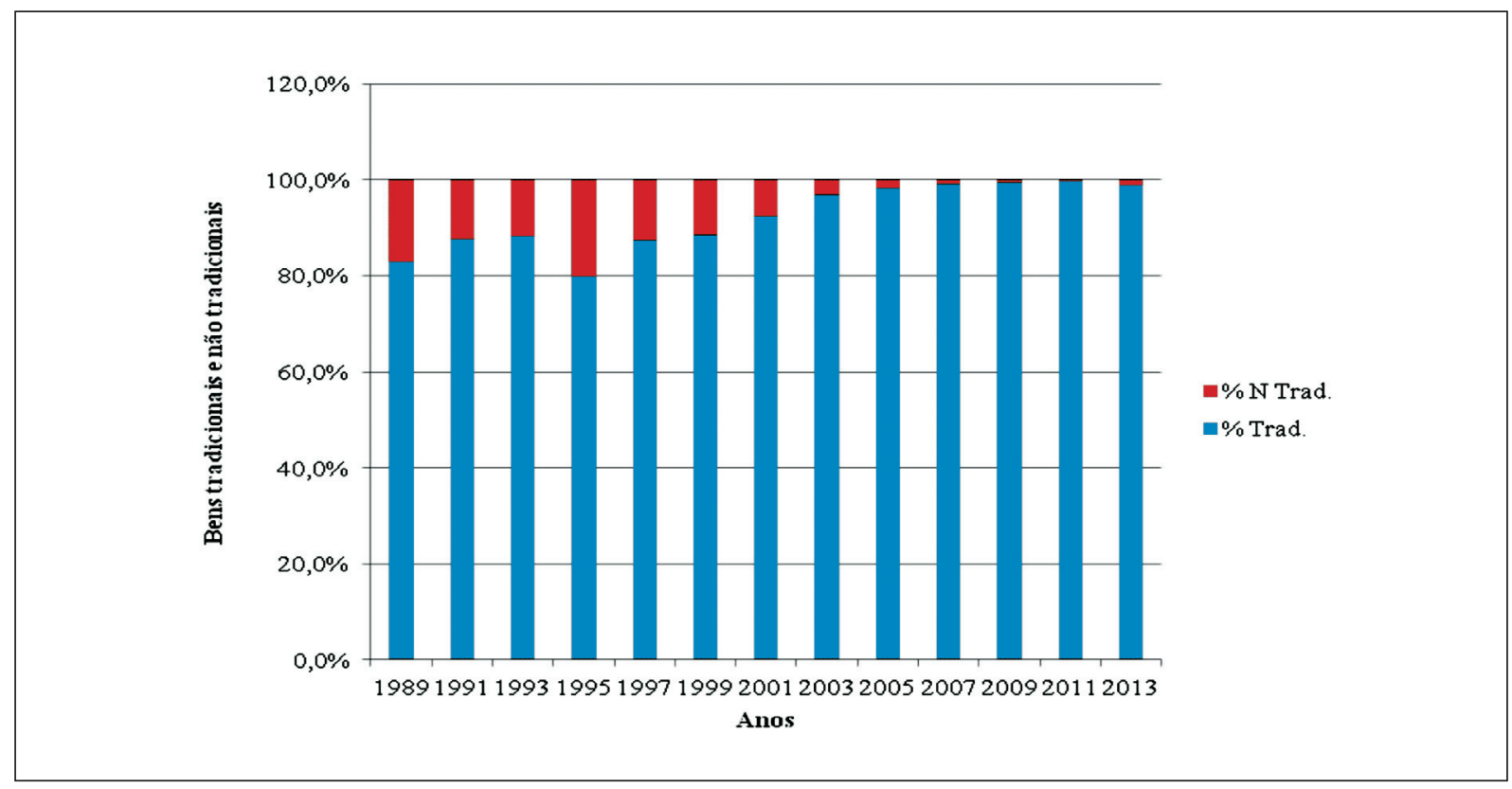

Fonte: Elaboração própria a partir de dados do ALICEWEB (2014).

Conforme a Figura 3 aponta, no decorrer do período em análise, ocorreu um aumento da participação dos setores tradicionais no volume total das exportações, elevando-se de 83\% em 1989 para próximo dos 100\% em 2013, havendo apenas pequenas oscilações até 1995, e logo em seguida apresentando comportamento ascendente. Uma vez que, de acordo com a função de experiência das exportações acumuladas, são tradicionais as exportações que apresentam o crescimento concentrado no final do período em análise, pode-se inferir que as exportações fluminenses serem em sua maioria tradicionais é um fator positivo para o estado, já que a possibilidade de que as mesmas continuem a crescer é maior, sendo menos provável uma queda nas vendas ao exterior.

Por fim, a Figura 4 apresenta a função experiência das exportações acumuladas para cinco grupos de produtos do Rio de Janeiro, nos anos de 1990 a 2013.

Figura 4

Exportações acumuladas do Estado do Rio de Janeiro (1990-2013)

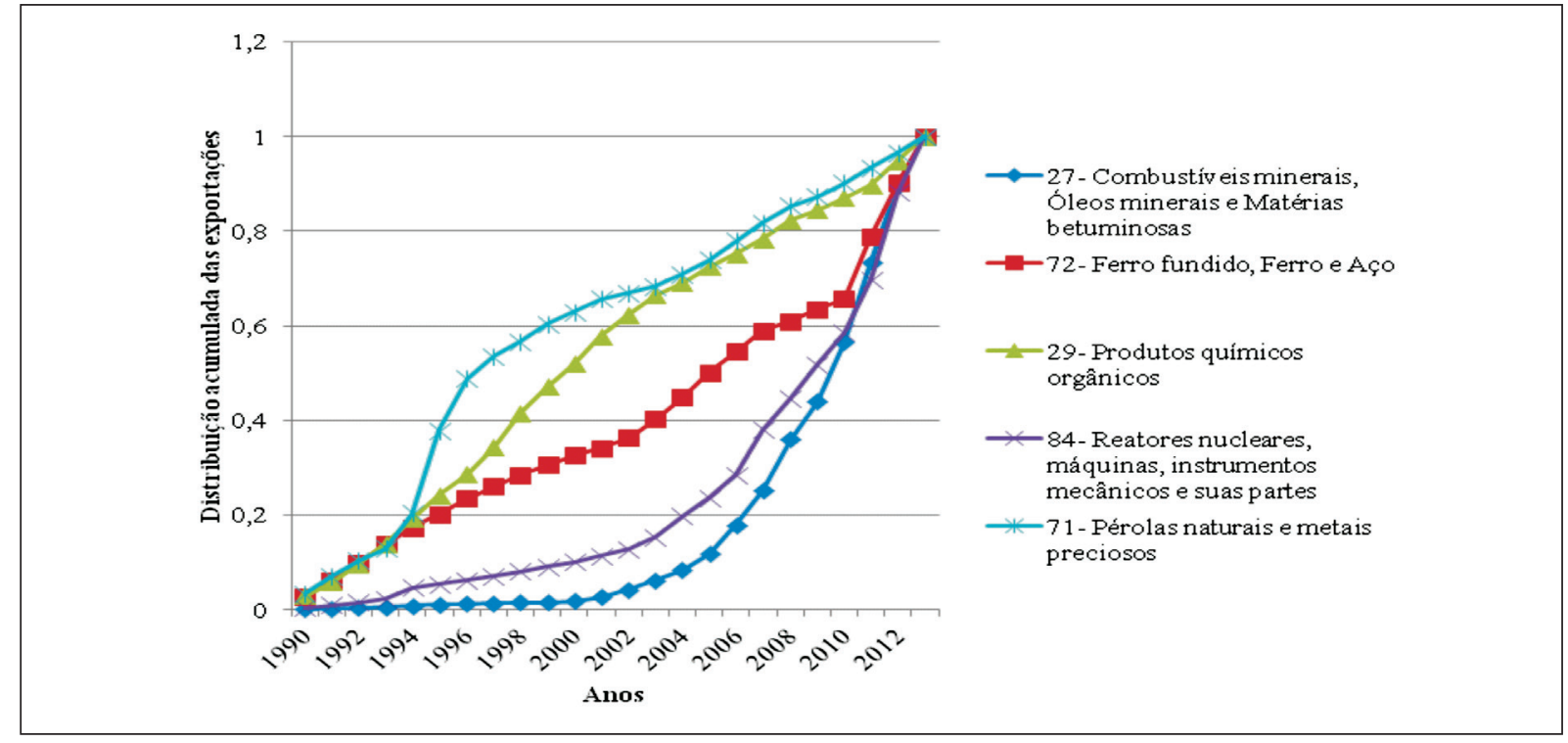

Fonte: Elaboração própria a partir de dados do ALICEWEB (2014). 
A análise dos resultados apresentados na Figura 4 aponta para o setor de combustíveis minerais como um setor tradicional, já que o maior crescimento de suas exportações se dá no final do período considerado. O mesmo comportamento foi observado para o setor de ferro fundido, ferro e aço e o setor de reatores nucleares, sendo ambos também tradicionais. Todavia, os setores de pérolas naturais e produtos químicos orgânicos, que também se destacaram na pauta fluminense, apresentaram o crescimento de suas exportações concentrado no início do período, logo foram classificados como setores não tradicionais.

De acordo com Silva e Hidalgo (2010), em sua análise para o Brasil nos anos de 1996 a 2005, o setor de combustíveis minerais é classificado como não tradicional na pauta brasileira, ao contrário do que ocorre nas exportações fluminenses. Um fato importante que os autores constataram, e que também pode ser observado neste trabalho, é que, entre os setores não tradicionais, figuram produtos que têm sua origem no setor primário. Por outro lado, os produtos tradicionais como reatores nucleares são produtos com maior valor tecnológico, considerados em sua maioria industrializados. Logo, o que se quer ressaltar é que não se deve associar o conceito de exportações tradicionais a setores de origem primária, nem tampouco o de setores não tradicionais a produtos manufaturados.

\section{Conclusões}

Nas últimas duas décadas as exportações fluminenses passaram por um vigoroso crescimento. Somente entre os anos de 2000 e 2010, esse aumento correspondeu a aproximadamente $1000 \%$, deixando evidente a necessidade de um estudo mais aprofundado da pauta exportadora do estado, para que haja maior inserção de seus produtos no comércio internacional. Para que tal fim seja alcançado, buscou-se analisar o grau de diversificação e de concentração da pauta exportadora do Rio de Janeiro.

O que se observou, ao longo do período de 1990 a 2013, foi uma queda na participação das exportações do grupo ferro fundido, ferro e aço, de média-baixa intensidade tecnológica e principal setor da pauta até o ano de 2001, e um consequente aumento da participação do grupo de combustíveis minerais, de média-alta intensidade tecnológica. Constatou-se também que esses setores são tradicionais nas exportações do estado. No Rio de Janeiro, assim como no Brasil, ocorre o domínio das exportações industriais de menor intensidade tecnológica, que, segundo Pinto (2011), se deve a uma especialização regressiva da estrutura industrial do país, excessivamente voltado aos segmentos intensivos em recursos naturais. Apesar dos Estados Unidos se apresentarem como principal parceiro comercial fluminense, o índice de concentração por destino não demonstrou forte associação entre este país e as exportações do estado.

Sendo assim, os resultados apontam para os problemas decorrentes de uma pauta exportadora concentrada em poucos produtos. A balança comercial do estado fica exposta a possíveis crises de demanda por esses produtos, que gerariam uma queda brusca nas receitas com as exportações. Portanto, é necessário manter a produtividade do setor de combustíveis minerais, contudo, deve-se evitar que a concentração das exportações nesse setor volte a sua trajetória ascendente, como forma de reduzir a dependência da região com relação ao desempenho no comércio externo de apenas um pequeno grupo de produtos. 


\section{Referências bibliográficas}

ALICEWEB - SISTEMA DE ANÁLISE DAS INFORMAÇÕES DE COMÉRCIO EXTERIOR. Ministério do Desenvolvimento, Indústria e Comércio Exterior. Secretaria de Comércio Exterior (MDIC/SECEX). Disponível em: <http://www.aliceweb.desenvolvimento.gov.br>. Acesso em: 17 jan. 2014.

DINIZ, F. Crescimento e Desenvolvimento Económico: Modelos e Agentes do Processo. 2. ed. São Paulo: Edições Silabo, 2010. 416 p.

FARIA NETO, M. M. de. Evolução na Indústria do Petróleo e Gás no Brasil e os Desafios da ANP no Atual Modelo. In: CONGRESSO BRASILEIRO DE P\&D EM PETRÓLEO E GÁS, 2, 2003, Rio de Janeiro. Disponível em: < http://www.univen.edu.br/revista/universo_petroleo_03.pdf\#page =5 > . Acesso em: 10 abr. 2014.

FURTADO, A. T.; CARVAlHO, R. Q. Padrões de Intensidade Tecnológica da Indústria Brasileira: um estudo comparativo com os países centrais. São Paulo em Perspectiva, vol. 19, n. 1, pp. 70-84, jan./mar. 2005.

KRUGMAN, P. R.; OBSTFELD, M. Economia Internacional - Teoria e Política. São Paulo: MAKRON Books, 2005.

LOVE, J. Trade concentration and export instability. The Journal of Development Studies, vol. 15, n. 3, pp. 60-69, 1979.

LUCCHESI, C. F. Petróleo. Estudos Avançados, 12. S.I, 1998.

MATTOS, F. A. M. de; CARCANHOLO, M. D. Amenazas y oportunidades del comercio brasileño con China: lecciones para Brasil. Problemas del Desarrollo, vol. 43, n. 168, jan./ mar. 2012.

MINISTÉRIO DO DESENVOLVIMENTO, INDÚSTRIA E COMÉRCIO EXTERIOR. Secretaria de Comércio Exterior (MDIC/SECEX). Dados sobre o comércio exterior brasileiro. Disponível em: <http://www.aliceweb.desenvolvimento.gov.br>. Acesso em: 17 jan. 2014.

ORDÕNEZ, R. Petróleo. Dependência Externa as Reservas Gigantes do Pré-sal. 2009. Disponível em: <www.oglobo.globo.com>. Acesso em: 03 dez. 2013.

PINTO, E. C. América Latina na primeira década do século XXI: "efeito China” e crescimento com inclusão. In: OICHDPP. Estudos e análises. OICHDPP: Brasília, 2013.

. O Eixo sino-americano e a inserção externa brasileira: antes e depois da crise. Texto para Discussão (IPEA). Brasília, v. 1652, pp. 1-60, 2011a.

SANTOS, P. R. Intensidade Tecnológica, Especialização Comercial e Competitividade: Uma análise da indústria de transformação do Nordeste. Dissertação de Mestrado em Economia. Maceió: Universidade Federal de Alagoas, 2011.

SILVA, J. L. M. da; HIDALGO, A. B. Composição e Diversificação do setor exportador brasileiro: uma análise do perfil das exportações. In: SOCIEDADE BRASILEIRA DE ECONOMIA, ADMINISTRAÇÃO E SOCIOLOGIA RURAL, 48, 2010, Campo Grande. Disponível em: <http://www.sober.org.br/palestra/15/879.pdf > . Acesso em: 10 abr. 2014.

SILVA, J. L. M. da; MONTALVÁN, D. B. V. Exportações do Rio Grande do Norte: estrutura, 
vantagens comparativas e comércio intra-indústrial. RER, Piracicaba, vol. 46, n. 02, pp. 547568, abr./jun. 2008.

SILVA, T. A. Desempenho da pauta de exportações agroindustriais de Minas Gerais. Dissertação de Mestrado em Economia Aplicada. Viçosa: Universidade Federal de Viçosa, 2005.

SOARES, B. T.et al. O Petróleo e a Economia do Brasil. Universo do Petróleo e Gás, Nova Venécia, vol. 01, n. 3, pp. 5-20, jul./dez. 2010. 